\title{
Converting Israeli Standard Occupation Classification 1994 (IL94) into International Standard Classification of Occupations 2008 (ISCO08) based on the European Social Survey
}

Eyal Bar-Haim ${ }^{12}$

\begin{abstract}
The Israeli CBS is using an occupational classification that is not easily convertible to international standards. Using ESS data from 2016, in which occupations were coded independently for the Israeli Standard Occupation Classification 1994 and the International Standard Classification of Occupations 2008 (ISCO08), I show how to convert the IL94 into the ISCO08. I demonstrate the pros and cons of using this conversion by comparing the ISCO08 into ISEI conversion as suggested by Ganzeboom (2010) and Semyonov, Lewin-Epstein and Mandel's (2000) SES.
\end{abstract}

\section{Introduction}

The importance of a cross-country comparable standard classification of occupation has been demonstrated in many comparative studies (Treinman \& Ganzeboom, 1996). However, the Israeli Central Bureau of Statistics (CBS) is using its own classification for occupation that is not easily convertible to other countries. The CBS suggests a crosswalk table to convert its classification into the now outdated ISCO88 classification (CBS 2010); however, the conversion of the IL94 to the ISCO08 based on this crosswalk is not simple and omits many occupations. Since 2015, the CBS presented a new classification - IL11, which is closely based on the ISCO08 (CBS 2015) and would solve the aforementioned problem. However, many datasets still contain the previous classification, which poses a problem for researchers wishing to integrate occupational data from Israel into their comparative studies.

This problem is even more pronounced when discussing socio-economic index based on occupational ranking. In 2000, Semyonov, Lwin-Epstein and Mandel introduced a socio-economic scale based on the IL94 classification. This scale is based on the median income and required education in each

\footnotetext{
${ }^{1}$ The Department of Education, Ben-Gurion University of the Negev

${ }^{2}$ I wish to thank Dr. Irit Adler from the B.I. Cohen Institute, who was very helpful in answering my questions regarding the process of acquiring occupational information for the Israeli subset of the ESS.
} 
occupation. As such, it is close in nature to Ganzeboom, De Graaf and Treiman's (1992) ISEI, but is not comparable, since the latter is based on regression estimations. Therefore, until now, ISEI ranks based on IL94 were not easily available.

Using the Israeli subset of ESS data from 2016, I introduce a crosswalk between IL94 and ISCO08. The crosswalk is available using the Stata package, ISCOIL. The package also contains the crosswalk from IL94 in Semyonov, Lewin-Epstein and Mandel's (2000) SES scale and from ISCO08 in Ganzeboom's (2010) ISEI scale. This enables me, using the Israeli 2010 Labour Force Survey (LFS) to compare the scales and to estimate its usefulness in comparative studies.

\section{The Creation of the Crosswalk}

The Israeli subset of the 2016 ESS dataset contains two separate variables of occupations. The first is based on the IL94 classification and the second on the ISCO08 classification. The B.I. Cohen institute produced both variables produced independently. The data contain 2,253 cases with valid occupations in both classifications. Comparison of the two variables demonstrates that about $60 \%$ of the occupations are uniquely identified. For the rest of the occupations, I used the mode IL94 occupation ${ }^{3}$ in each ISCO08 category. The result is a crosswalk of 188 categories of ISCO08.

\section{Testing the Crosswalk}

Using the LFS 2010, I converted the data of occupations (IL94 based) of 43,458 individuals and their spouses into three variables: ISCO08, Ganzeboom's ISEI and Semyonov, Lewin-Epstein and Mandel's SES. Thus, I was able to compare the usefulness of the conversions: first, I compared the correlations between ISCO08 based ISEI and IL94 based SES and their correlation with years of education, and then I compared the correlation between ego and spouse in each classification. These results are presented in Table 1.

\footnotetext{
${ }^{3}$ The ILO suggestion is to use the $80^{\text {th }}$ percentile of occupations. However, due to the relatively small sample, I opt for the more liberal option of the mode.
} 
Table 1: Pairwise Correlations Between Different Occupational Classification

\begin{tabular}{|c|c|c|c|c|c|c|}
\hline & \multicolumn{3}{|c|}{ Ego } & \multicolumn{3}{|c|}{ Spouse } \\
\hline & & SES & ISEI & $\begin{array}{l}\text { Years of } \\
\text { education }\end{array}$ & SES & ISEI \\
\hline \multirow[t]{6}{*}{ Ego } & SES & 1 & & & & \\
\hline & $\mathrm{N}$ & 41159 & & & & \\
\hline & ISEI & $0.9065 * * *$ & 1 & & & \\
\hline & $\mathrm{N}$ & 41159 & 41159 & & & \\
\hline & Years of education & $0.3101 * * *$ & $0.2974 * * *$ & 1 & & \\
\hline & $\mathrm{N}$ & 41159 & 41159 & 110000 & & \\
\hline \multirow[t]{4}{*}{ Spouse } & SES & $0.2114 * * *$ & $0.1836^{* * *}$ & $0.1428 * * *$ & 1 & \\
\hline & $\mathrm{N}$ & 8432 & 8432 & 14380 & 14380 & \\
\hline & ISEI & $0.1241 * * *$ & $0.1056^{* * *}$ & $0.0694 * * *$ & $0.7159 * * *$ & 1 \\
\hline & $\mathrm{N}$ & 8432 & 8432 & 14380 & 14380 & 14380 \\
\hline
\end{tabular}

$* * *-\mathrm{p}<0.001$

The results indicate that ISEI and SES are highly correlated with each other $(\mathrm{R}=0.9)$. Both variables are also similarly correlated with years of education, albeit the SES performed slightly better ( $0.31 \mathrm{vs.}$ 0.29). Regarding the correlation between ego and spouse, the SES variable performed considerably better (0.21 vs. 0.10). However, the sign and significance were the same.

Finally, I regressed years of education and occupation, based on IL94 and ISCO08. I regressed the years of education by the occupational categories as a set of dummy variables and compared the adjusted $\mathrm{R}^{2}$ produced by each classification. The results are presented in Table 2 .

Table 2: Summery of Linear Regressions Predicting Education by Occupations Categories Dummies

\begin{tabular}{lllll} 
& \multicolumn{5}{c}{ Adj R $^{2} \mathrm{~N}$} \\
\cline { 2 - 5 } & ISCO08 & 0.1135 & 41,159 & $* * *$ \\
IL94 & 0.1166 & 43,458 & $* * *$ \\
$* * *-\mathrm{p}<0.001$ & & & & \\
\cline { 2 - 5 } & & & &
\end{tabular}


Here, the IL94 classification performed slightly better $(11.66 \%$ vs. $11.35 \%)$. The very small difference between the explained variances can be attributed the smaller sample for which the ISCO08 variable had information.

\section{Conclusion}

Every conversion of occupational classification has a price regarding the loss of information. However, for some types of studies, namely comparative analyses, this cannot be avoided. In this report, I demonstrated the loss of information that might be the result of using the ISCO08 converted from IL94 using the ILISCO Stata package. The package seems to be useful when the loss of cases due to the conversion is relatively small.

Moreover, when further converting the ISCO08 to ISEI, and comparing it to the SES index, there was a very strong correlation, implying that these are almost interchangeable. Hence, the use of ISEI is preferred in many cases due to its comparability over countries and potential for future research.

\section{References}

Central Bureau of Statistics (CBS) (2010). The Conversion Key from the 1994 Standard Classification of Occupations to the ISCO-88 Classification. Jerusalem: The State of Israel

Central Bureau of Statistics (CBS) (2015). Standard Classification of Occupations 2011. Jerusalem: The State of Israel

Ganzeboom, H. B. (2010). A new International Socio-Economic Index (ISEI) of occupational status for the International Standard Classification of Occupation 2008 (ISCO-08) constructed with data from the ISSP 2002-2007. In Annual Conference of International Social Survey Programme, Lisbon (Vol. 1).

Ganzeboom, H. B., \& Treiman, D. J. (1996). Internationally comparable measures of occupational status for the 1988 International Standard Classification of Occupations. Social science research, 25(3), 201-239. 
Ganzeboom, H. B., De Graaf, P. M., \& Treiman, D. J. (1992). A standard international socioeconomic index of occupational status. Social science research, 21(1), 1-56.

Semyonov, M., Lewin-Epstein, N., \& Mandel, H. (2000). Updated socioeconomic scale for occupations in Israel. Megamwt, 40(4), 706-729.

Appendix

Stata Do-File

scc install iscoil // ISCOIL Stata package, containing iscoil, ilses, isco08isei

** Ego

iscoil v68, isco(isco08) // Converting IL94 occupation into ISCO08

ilses v68, ses(ses) // Converting IL94 into SES

isco08isei isco08, isei(isei) // Converting ISCO08 into ISEI

** Spouse

iscoil v69, isco(isco08_p) // Converting IL94 occupation into ISCO08

ilses v69, ses(ses_p) // Converting IL94 occupation into ISCO08

isco08isei isco08_p, isei(isei_p) // Converting IL94 occupation into ISCO08

pwcorr ses isei_1 v57 ses_p isei_p, star(0.05) obs

reg v57 i.isco08

destring v68, force gen(i194)

reg v57 i.oc94 